\title{
The Trilogy of a Digital Communication between the Real Man, his Digital Individual and the Market of the Digital Economy
}

\author{
Wendgoudi Appolinaire Beyi
}

$\mathrm{PhD}$ Student in Communication, University of Ouaga 1, Professor KI-Zerbo, Independent Consultant in Management, Communication, Psychology, HRM, Burkina Faso

\begin{abstract}
The place of the activities coming from the market of the digital economy is inevitably similar to that which they occupied in the real activities of the traditional economy. By creating virtual links, the new economy creates an order of communication that structures relations with others and the relation to oneself in a new dynamic: the digital individual in the new interactions is reconstituted between a free and autonomous individual superimposed a virtual individual unified to a virtual world.

The new communication or digital mediation raises questions about the relationship between the individual and the digital, the new form of economy, that is, the individual imbued with digital mediation in the form of a new market for the structuring economy. The new form of communication in the new form of social (more subjective) and technical interaction imposed by the digital economy market deserves an analysis.

This analysis focuses on the characteristics of communication with the new order of mediation, the culture of the individual emerging in the culture of the flourishing economy through the digital market: the trilogy of communication with the Internet between individual, the digital and the economy.

Thus, this reflection leads us to the evidence of a new social and economic order in terms of behaviors, attitudes and social governance of the new social identity. To this, we retain a number of recommendations that deserve attention at the level of international, national, local and identities governance to ensure security, dynamism, an interactive and confident human network, a deployment of the ideal human of uniqueness by the virtual. Among the recommendations, we have: at the technical level, it is the use of the technical multilinguistic conversion of contents as a new market mediator tool and consequently of international and global social dialogue; at the political level, it is the acceptance of a new identity and security interface; at the moral level, it is the question of the censorship of the interfaces taking into account the variety of the users and sensitivities of the contents for each users.
\end{abstract}

Keywords: digital mediation, communication, digital economy, virtual, network.

JEL Classification: Z, Z1.

(C) The Author, 2018. This article is published with open access at Sumy State University.

\section{Introduction}

The digitization of economic activity is more than the deployment of a technology, a theory or an economic doctrine, it is a new implantation of an independent media (digital mediatization) between the individual and his actions and therefore, between the individual and himself.

In the image of the internet, platform of the information and the updated communication, the digital structure the individual by the craze towards the market of the digital economy. At this level, it makes communication a preponderance of virtual analog with a global scale, leaving digital communication a place of hybridization or format error in the new communication: it becomes a form of payroll information to any user in the interface with the new autonomy and interaction contract. As a result, digital technology is a dynamic engine that gives the individual autonomy in a process of creating an identity without identity.

The market of the digital economy is replacing the market of the traditional economy which has, through time structured the order of social interactions, communication and the definition of the characteristics of man.

A series of questions can therefore be considered: How are interactions structured or digital mediation structured? Can we talk about the uniqueness of human culture? How to define the digital individual?

It would be relevant for us to have a configuration of societal structuring imposed by the systemic structuring of the digital market economy in order to predict the digital individual in the new global governance. 
The objectives of our analysis would therefore be to assess and describe the context of the digital revolution, the digital economy and the digital man in the governance of digital technology, and then predict the causal relationships in the inference trilogy. Finally, we consider the recommendable measures.

Our objectives thus located, it is important for us to impose an analysis strategy.

Our approach: Our approach to apprehend virtual underwear

Our research strategy is documentary study because resources are abundant on the issue of digitization, the digital economy and the articulations of the individual in his living environment. The thematic on the digital in the economic and social stake therefore takes a place in this analysis.

The subject of analysis consists of scientific articles and production, reflections and legal texts, as well as legal provisions of governance. The evolution of the debates thus presents the whole corpus and the analyses made.

However, the analysis also allows inferences to predict the configurations of the trilogy of digital mediation, the digital man in the digital economy.

Ultimately, it is a step to understand the structural and functional context of the man in the digital economy to register the identity logic of the new man. It is therefore a qualitative study of explanatory and predictive type that we envisage for this reflection.

In order to provide a predictive logic, we can put three orders of assumptions on the basis of the trilogy of a digital communication between the real man, his digital individual and the market of the digital economy.

The first evokes a structuring of interactions: it is digital communication or digital mediation.

The second stipulates the uniqueness of human culture: it is the determinism of the market of the digital economy.

And the third assumes the evolution towards the creation of the digital individual: it is the rise of the virtual individual in the duality between the social individual and the virtual individual.

\section{A current concern: the societal structure}

The analysis aims to situate digitization in the process of communication in the new socio-economic dynamics of the individual and to inscribe a deep analysis on its structural, structuring and dehumanizing consequences (without a debate on ethical considerations).

This structuring is proving to be relevant by economic convergence of all the actors of the economy, by the power of the digital media. Thus new factors or determinants of social regulation appear by proxy or failure. This underscores the absence or deficiency of global institutions that are expected to take over regulation.

However, would this regulation not be unnatural for the new digital mediation?

Our concern is based on this space of economic and social deconstruction, but above all on structures of interaction through the new communication that we identify through the concept of digital mediation. This space is established on the paradox of the new economy and the new individual with the reason of the communication disappropriated and dispossess by an analogical communication, fortified and a reduced digital communication in simple of drawers with information. All the economic functions with the digital are not only informational, they inspire to vital functions: that of mobilizing the individual in his daily life and even to inscribe a new cognitive DNA by a communication through the powerful media, the digital mediatization. Digital media is any medium of substitution of the act of the individual by a virtual act integrated into a digital and economic system.

As much as the digital economy and the material economy are contradicted in a form of hybridization of the economy, so much the real human and the virtual human is constituted in a hybridization of nature by redefining itself a sublime duality. The question of the transposable character thus lies between the phenomenon of the real being and that of the virtual being thus rendering a double personality and personification of the new individual.

The main question relates to: the modern design of communication in the market of the digital economy and the culture of man in the virtual environment.

Thus, subsidiary questions can be positioned in the perspective of our analysis: 
1) The digital is lost in the analogy of the design of the communication recorded by the digital

2) Interfaces like social networks as engines of virtual analogy that replaces real analogy

3) Human culture in the economic, social, digital and global technological culture

4) The decentralization of the tool that is courting the existence of private club or community, identity artifacts and commercial intermediaries?

5) The advent of a bipolar individual in a new order of a new communication.

\section{Our framework of analysis: a global concern}

Several researches have been included in the debate on social and societal mobilization around the process of digitization of the economy. Four axes can guide our analysis: the axis of the structured and structuring digital market economy, the axis of social and societal evolution, the axis of the influences of the new digital environment on the individual.

Like many authors on the question of the digital economy, Boureau and Penard (2016) ${ }^{1}$ as an introduction to the question of the digital economy, evoke the digital revolution on its technological foundation with the transmission capacity and data processing, the development of artificial intelligence and connection of objects, its economic foundation with powerful economic actors, its social foundation with the new formulas of sociability and collective action. With them, we agree that the economy of countries is inevitably unified and converted to digital: for example, consumers of digital communicate, seek information or buy with digital services such as Google, Facebook or Apple, Messenger, Whatsapp, etc. ; training offers such as Moocs gradually take the monopoly of education and teaching; specialized sites such as TripAdvisor or Booking.com etc., mobilize specific service operators.

In the construction of a comfort of the digital economy, in France for example, the law ${ }^{2}$ for a digital Republic is constituted in the process of "freeing innovation", "creating a framework of trust", "building a Open and inclusive digital republic ". In the example of these national measures among many others, this French dynamism of constitution of a digital republic does not bear a fragile foundation in this global and globalizing digital universe?

Even if the European Union, at the community level, plays a decisive role in the foundations of the digital revolution in its community by "defining the rules applicable to telecommunications in Europe", "protecting consumers", "setting technical standards By "supporting research and innovation", etc., the challenges of the open digital market require a more inclusive and integral governance of these societal tools for our part. The 'road map' ${ }^{\prime 3}$ for the digital single market that the European community has developed can therefore be fragmented in the global environment of the digital economy.

Several projects bear the responsibility of expanding the boundaries of the "digital republic" in community spaces. The example of the Intel World Ahead program of the US-Africa partnership strategy ${ }^{4}$ has already helped more than twenty (20) million new digital consumers in Africa zone in nearly fifty (50) countries. By promoting integration into the digital world for all vulnerable communities, the digital revolution is endowed with assets to inevitably enroll everyone in the digital process, the process of new media coverage, therefore, the construction of the trilogy: digital mediation, the digital man in the digital economy.

\section{The naturalization of communication: the reintegrated analogy}

The entrenchment of the means of globalization of communication, of digital mediation of interactions and monopolization of the economy by the digital media leads to a specific culture of communication with others

\footnotetext{
${ }^{1}$ Bourreau, M., et Penard, T. (2016). Introduction. L'économie numérique en question. Revue d'économie industrielle, 156(4), 11-15.

${ }^{2}$ La loi pour une République numérique, promulguée le 7 octobre 2016, France. Repéré à : economie.gouv.fr.

${ }^{3}$ The EU and the digital single market, (June 2017). European Commission, Spotted at https//ec.europa.eu/commission/priorities/digital-single-market_fr.

4 "Intel Word Ahead Program is connecting the next billion people to 21st century opportunities by improving access to technology, high-speed internet connectivity, effective teaching and learning, and relevant local content. Intel collaborates with local and worldwide leaders on a comprehensive, long-term approach that positively impacts lives and creates sustainable development". Presentation, Spotted at www.intel.com.
} 
and with oneself: the market of the digital economy implements itself with a model of analogical communication by substituting for the digital one as well the speech as the relational mode.

Usually, the needs arise spontaneously and orient the action in principle, however the market of the digital economy builds the need in a foundation aroused and led by the implicit and often anonymous suppliers and consumer prescribers. The environment of interactions is prone to a centrifugal or centripetal logic of the trunks of the economy in the digital market but also led by a deployment of a common language that is realized in an analog process of exchange and recognition of social artifacts, labels, indices or economic identities. Nevertheless, this recognition of differences does not carry an identity mark.

If the previous revolutions of human-to-human communication had deployed a digital culture of human exchanges with the local, national, regional, and continental economies, this revolution exercised by digital mediation intensifies a process towards which we can call the naturalization of communication. Thus, globalization with digital technologies and the similarities or uniqueness of the systems of economic, social and societal exchanges enrich naturalization or analog communication integrated into the device of the human cognitive system.

To exchange with the world, to sell or pay for a product, the most reliable way is the analogue because it abounds a multitude of facets converging any belonging or any community of language or linguistic culture. Thus, the functional center of communication economy has redefined a logic of communication between men that, however, may lead to a re-evaluation of the diversity of human culture in future generations.

Communitarianism was the main reason for creating cultural convergence of exchanges, linguistic discourses and means of exchange. The reason for the exchanges was humanistic and humanizing, even with the different sequences of exercise of political, social and economic doctrines.

The market of the digitized economy with the commercial exchanges and the necessity to register a virtual center of exchanges between the individual contributions or of economic entity with the common vitality, establish the capital like the engine of the exchanges, thus making the exchanges more technological than the place of material exchanges. This market dehumanizes interactions even in its virtual space.

The individualism or rather the autonomy which accompanies this process with the motive of valorization of the individual has finally put the human in boxes of his own consciousness or thought after these long conquests of the diversified human characteristics on several levels of community and generation: effect of social environment, city, country, region, continent, inter-continent, world but also the implication of the progress of a technological, social, cultural generation to other generations of the same orders.

The new form of international capitalism is establishing itself by capitulating the conventional lodges of trade circuits and the human perspectives of relations: individuals move away from each other with means of exchange and competition bias and this invites technological modeling of interhuman discourses.

With this new definition of a single language as a hub of exchange engines, analogue communication is more permissible with the expansion and integration of digital media into human activities: the autonomy of the digital individual inscribes its analogical dimension in the use of the drawers of information constituted by digital communication.

A new format of access to the knowledge of the object of the language is specified with a technological device always renewed in the quest for an iconic performance of the object. Can we speak here of the new language of digital mediation?

The cost of time in measuring the effectiveness and performance of a communication is a challenge of modern life and thus presents a further reason to make communication more serene in an analog discourse, therefore, the discourse of the most efficient and performant technology.

Each of the clues of communication takes the most accessible design so that the other in its sociolinguistic categorization box can evaluate its meaning without multiplying the intellectual exercises of identification and addressing through the content of the semantic memory. 


\section{Naturalization of identity: a culture of the digital individual}

The anthropologist Edward T. Hall has studied the distance between people by locating an intimate sphere (15 centimeters to 45 centimeters), a personal sphere ( 45 centimeters to 1.2 metres), a social sphere (1.2 metres to 3.6 metres), a public sphere ( more than 3.6 metres).

In the new dimension of interaction, the different spheres are confused giving rise to a situation of anonymity of the person in a public sphere. Thus, in this dimension of interaction, the person interacts in relative emotional indifference.

Moreover, it is obvious that man is an individual who develops geographical and spatial extensions and the modification of his habitual process generates a new definition of the dimension of his culture. At this level, the evidence is the emergence of a global culture of the digital individual.

There is an injunction of the notion of overcrowding with, on the one hand, the complex technical networks of the economy market and, on the other hand, social motives with a universal culture such as social networks.

The boundaries between the perceived and the external environment are redefined in the highways of the usual technical networks and the relationship to a real physical environment, emotional, even existential.

Game applications replace the need for real and symbolic play in children, and these new universes even catch teenagers as the fortification of the same symbolic universe.

The gaming market has therefore become an economic convergence. While the symbolic play at the level of the childhood period in the constitution of intelligence and surrounding social practices undergoes the effect of this prescription of the digital mediation: the guarantee of a universal reproduction of symbolic relations or symbolic mediation is obvious only a hypothetical social, societal or cultural reproduction of symbols or symbolic mediations linked to a real socio-cultural environment of the individual.

Integrated linguistic and language discourses are increasingly depersonalized through digitization. In the example of Google integrated translation, the translation options include a more scientific, more technical, and therefore more universalizing discourse. Linguistic codes, linguistic or cultural resources disappear in this new communication with technological innovations in vogue. Human linguistic wealth in this perspective borrows the codes usually devoted to electronics or digital elementary.

Google Translation is therefore the prototype of the latest generation of technical but human exchange platform, with the oral, written, and even visual modalities in the new communication between different linguistic communities without accepting a form of cultural identity or linguistic rhetoric.

The Peta byte (measurement of all the data, product data of the world) thus becomes a unit of human culture with at the beginning the byte (binary values, the bit, 0 or 1 , universal alphabet) and brings together the world to establish a zone of intelligence outside the sociocultural space of the human and that at the service of a unification of humanity around the unreal virtual individual by the "digital mediation".

In the new paradigm of change that is taking place, it is clear that digitization creates a new extra world, with new characteristics in the permanence of the cognitive, of the universal cultural, of the identical system of values in a single economic system. This new world is superimposed on a real world of the individual who is crumbling to create a virtual and universal self.

The Internet is a supreme point of accumulation and informational radiation and by integrating telecommunications and informatics, the virtual world creates a center of exchange whose economic and sensational remains the engines of the convergence movements of the individual and various community formats.

By constituting a norm of configuration of the communication and figuration of the information, this global technology structures the human relation by reconstituting the individual in a virtual dimension intersubjectivity in mutation.

Can we speak of an inter-objectivity in the new relational form imposed by the virtual communicative or the digital mediation? What is obvious, the challenge of communication is performed by this digital mediation.

The intersubjective suggestion in the relation of reciprocity disappears in this form of communication, thus making a preponderant place for an autonomy of the individual in his impersonal and often ephemeral community addresses. 
However, this autonomy is the illusory substitute that this technology accords to the new generation of human passionate and dazzled by its uses: each is alternately client implicit or explicit and information server in the various operations of digital mediation allowed.

A mental map of humanity is constituted around each innovation of the tools integrating the digital mediation, the new applications or the programming creator of codes and rituals, which are related and integrate easily with this conceptual device, virtual and cultural unified.

The example of the effects of the game applications mentioned, which take an enormous proportion in the constitution of the thought of the new generation, also constitutes this substitution of the foundations of the transmission of the values of the education of the communities from one generation to the next other but especially of this form of regulation of the cognitive and affective system towards a homogenization.

The encounters of cultures facilitated by identity concepts in games become an objectification of encounters because the other is not perceived as such with intrinsic values in these inter-objective circumstances of encounters but perceived in its impersonal, virtual form. This appears, then, as a decadence of culture in its diversity towards a unique identity base and another nature of the human performed by digital mediation.

This new form of acculturation or enculturation opens up to a virtual culture beyond the signals of necessities or realities of each individual: the objectification leading to the virtual is superimposed on the subjectivity of the reality of each and this creates a tension that we can call a dissonance of the human person or the new duality of human nature.

The individual splits into this logic and the community loses its impulses of communion leaving the only alternative to a creation of the world community. And any community that does not turn to this achievement is doomed to remain isolated and obsolete.

In reality, nations that maintain undifferentiated values and identities themselves exist only on the basis of the coercive force they have to counter the universalization of values and landmarks. The individual is in the prescription of the virtual than in that of policies concocted by political leaders who struggle to impose themselves in the leadership proscribed by the autonomy reserved for individuals and virtual solidarity.

The more evolved socio-political, cultural and economic models present local models in disuse, and legitimately inspire revolt, frustration, and change at all, at a speed of breaking with realities surrounding areas: this is the effect of the identity crisis.

It is no longer a question of questioning a digital culture but of accepting the evidence of a universalizing or so-called numerical cultural identity: the dominions of the cultures of the favored classes are dissipated in the existence of the frames impersonal encounters (Facebook, MySpace, Twitter, etc.) where the individual no longer has a social rank but a digital identity. Will capitalism in its traditional economic and social doctrine survive under these conditions the new economic and social doctrine coming from a digitized capitalism?

The vital infrastructure for the new global economy is built on impersonal foundations with the digital mediation, this new individual with a global identity: the man from everywhere, is the new virtual nature of the human which inspires therefore a creation of the new man by digital mediation prescribed by the foundations of the market of the digital economy.

\section{Denaturalization of the human: the substitutes of emotions}

Do human relationships become virtual relationships? Is trust thus an illusion accepted and reinvested through digital mediation?

At the end of each link of digital mediation to the image of the Internet is an interlocutor, customer or seller of product, service, virtual, illusion or trust in a facade of neutral reciprocity.

The marks of writing, images, videos, emotions are all exposed to falsehood by technological perfection and the recession of truth by the very nature of digital mediation. The market of the digital economy is superimposed on the market of the real economy by substituting market truths for truths of applications or intangibles. The real individual is constituted a virtual individual to be in the effectiveness of the market of the new digital economy.

As much as affections are tied in the virtual dimension, sex or sensuality takes a virtual proportion with different offers of shopping pleasure on the internet: each interlocutor with the digital mediation is an anonymous 
who shares our illusory intimacy in a network. Fantasies are erected at the risk of enriching one's own illusions to remain such: the flirting man remains convinced of the surreal nature of his very relationship but he pays the price, the courting is not convinced of the characteristics of his interlocutor and yet remains affected by unreal emotions. Thus, the sensational is more in the virtual than in the reality of everyday life.

The economy of the surrounding sex is deployed in virtual sex economy. The digital mediation creates a reason for sublimation of real emotions by sensational emotions, virtual and therefore superficial. And the philosophical question of the reproduction of future generations arises in terms of humanitarian problem with the transfer of virtual sexuality to real life. Will sensual sex toys with a powerful visual have an easy insertion into a new virtual home format?

The new market form of the digital economy is co-dynamic with the new form of illusionary digital mediation. This duality conveys the interests of the individual towards virtual economic, social and societal issues contrary to the previous logic in which the stakes implied an awareness of reality. Thus, man is in the trap of the virtual, condemned to pay virtual first to acquire the illusion of reality: it is the superposition of the real emotions of the new identity of the digital individual with emotions sublimely virtual.

\section{Digital mediation and decomposition of cognitive DNA}

In this market of the digital economy, the technology renews its performance in the installation of digital infrastructures or digital mediations to reach the installation of the individual in the virtual universe. With these infrastructures or mediations, everything is gradually becoming part of the world of digitization: from human activity to robotization, the new economy integrates remote control of the controls of the real means of production.

Digital work refers to an invisible activity that generates content and metadata. The work becomes more value creation than product in this perspective. This generalized process also leads to a question about real production when most actors in the real economy are part of the dynamic production of content and metadata with the risk of substituting the dynamism of real production with a virtual creation. of values.

This is the era of a dispossessed and unified communication: the usual use of the schemas of communication takes and makes its usual meaning now: digital mediation or the new communication. The relation of man to the virtual in the construction of social and economic links and the deposit with possible withdrawal of digital content and not transaction (in the sense of exchange of real emotions) of content previously admitted. True analogy is a substitute for numerical analogy, and digital is an accessible resource and not a logic of a dynamic process of communication.

The determinism of the tool of the digital communication or digital mediation is essential as a tool of socioeconomic construction and deconstruction, cultural and indirectly, the culmination of a design of a virtual man in a virtual world environment: the new man was born then in the defragmentation and that, with a free body and real but of a unified spirit to the world and chained to the virtual one.

Could the Internet at the end of the new world culture meet the challenges of the multiple failures of wealth and previous cultural diversity?

The cognitive DNA, of the mind or of the thought, is externalized to the individual at this virtual level to make room for the new procreation. The determinism of each digital mediation is for each user a communication infrastructure according to the uses of these same digital mediations. And it is the digital economic models that identify by their inherent attractive forces, the deployment and development of virtual DNA: multifaceted platforms that connect several groups of customers, the premium model that activates and nourishes the taste, the lead-line model that distributes the intangible product, the open or collaborative model that makes entrepreneurial autonomy of entrepreneurs independent of conventional contracts or geographical or socio-political situations. To all these competitions in terms of economic infrastructure is superimposed a "design" meeting identity of the virtual man: an identity that each individual invested and associates.

Digital apotheosis is thus the drift of the previously defined communication, the substitution of the relation between men by a link between them, an access to a content that a transaction equipped with emotions: the erosion of the nature of the communication is realized in the expiation of the feeling of the individual, his emotions towards a self, other than oneself: the digital individual superimposed on the individual in himself. It is the decomposition of the cognitive DNA of the individual to reconstitute itself in a network of global cognitive DNA on the effect of the new economic dynamics. 
By evoking the Millgram paradox, it is obvious that individuals can be connected to any other individual without a decisive social chain of relationship and that is why the relationship becomes an autonomous selfrelationship as well. This new communication, by making these connections technical, constructs a form of perception of oneself and the other in these interactions without interactions.

\section{The concerns and applications of our analyses: what devices for such identical universe}

In this analysis, which we have been good enough to undertake, we have evoked three hypotheses on the basis of a principal calculation. After our analysis, each hypothesis is confirmed and positioned in a very positive comfort.

We have therefore noted evidence of the structuring of interactions, and this also places the existence of digital communication or "digital mediation" on the main point of our hypotheses. The uniqueness of human culture is revealed as inclusive in the new global and globalizing market. The determinism of the market of the digital economy marks the confirmation of the second hypothesis in its position as the dynamic center of our hypotheses.

The evolution towards the creation of the digital individual is therefore comfortable in our scientific prediction. The rise of the virtual individual in the duality between the social individual and the virtual individual is finally a result of the digital revolution on the foundation of the global digital economy market.

Thus, our main hypothesis is confirmed by the trilogy of a digital communication between the real man, his digital individual and the market of the digital economy.

These methodical observations impose on us a certain number of practical recommendations to the international community but also to the manufacturers or operators of the technological in the evolution of the constructions of the digital universe in order to re-register the digital man in his human dimension.

We therefore recommend:

To the political and moral community, to deconstruct and reconstruct access to the contents of information and data, access to services on the basis of the controlled identification of each digital user by a digital key or a code "Evolving with the age of each user: the references of passports or identity card holds right of access to a key". This builds a world digital republic controlled by international legal persons. Thus, the issue of scam or digital security would be a given.

To the moral and ethical community we recommend that we defend a policy of user access by common references and ethical values that are acceptable according to the maturity of the users. It is also a question of enriching the contents of human values of solidarity and responsibilities.

To the security and regulatory community of the possible technical device and international use, to work to impose the responsibility of each user on its uses on the basis of traceability of their actions through the use of the digital key referenced.

Thus, we believe that the new digital man is equipped with a global, human identity and a responsibility of use and action in this new free societal universe. It is therefore to impose a card and an identity to the digital man for a reliable database and a rational and mastered use of the tool.

\section{Conclusion}

Geert (Hofstede, 1991) ${ }^{1}$ points to four dimensions in order to display benchmarks of cultural variability: the prevention of uncertainty, which is the degree of anxiety and uncertainty with which members of culture feel at home. the distance to power that lies in the degree of valorization of unequal power relations between different social roles, the masculinity or femininity of a culture (the masculine culture differentiates the roles of the two sexes), the orientation short-term or long-term culture (long-term orientation manifests the thrifty or persevering play in the individual, which differs from the short-term orientation that values tradition, turned to ritual - the past or action-oriented reciprocity). The test of digital mediation in the constitution of the new universal culture that we have just experienced throughout our analysis raises the ineffective aspect of these benchmarks. This further builds the hypothesis that the digital individual has a universal culture in the foundations of the new form of market of the economy built by digital. 
Alexander (FRAME, 2008) ${ }^{1}$, also interested in culture, spoke of the role of culture at the level of cognition in terms of cultural cognitive structuring. This dynamic in the cognitive constitution by the new communication or digital mediation certainly inspires a structuring of the autonomous individual in relation to his environment but inevitably attached to a larger and more imposing environment. In this perspective, Kaufmann, J.-C. $(2004)^{2}$ already challenged, the foundation of objective identities attached to social foundations to evoke the evidence of subjective identities in expression in our modern societies. With the new economic market and the new communication, the real identity pretext is replaced by an impersonal identity, universalizing, and therefore unreal.

In the end, the analogy is set in the process of linking to the other both present and absent, the digital is the new form of mediation that substitutes real analogy in virtual analogy universally integrating and integrated, the digital is is in drawes of information, the human culture is substituted for the economic culture by the attraction, the vitality, the necessity and the new imposing communication. Finally, the individual is divided between the real self and the subjective self (in the perspective of the subjective identities of Kaufmann, JC), but especially between the self (real and subjective) and the unreal self (objective and universal): the digital mediation or the new communication creates the digital individual in the trilogy of the economy, the digital and the individual.

To progress in our remarks and in order to note the obviousness of this impersonal structure of the speech in the new communication, we translated this text from French to English with the help of Google Traduction. Thus, as you have seen in our remarks, rhetoric gives way to semantics in this new communication with this tool integrated into the system. This helps to build the identical individual in the discourse, thus the virtual and universal individual and identity.

To end this reflection or this analysis on the paradox of the digitization of the economy and the digital mediation between individuals and with themselves, consider a simple philosophical reflection: "will not the new man be born, identical everywhere like stars in the sky that looks alike but never touched ... End of the story".

\section{References}

1. Chevrier, S. (2003). Le management interculturel. Paris, PUF.

2. Edward, T. H. (1979). Au-delà de la culture. Seuil.

3. Frame, A.(2008). Repenser l'interculturel en communication. Performance culturelle et construction des identités au sein d'une association européenne. Science de l'homme et Société. Université de Bourgogne.

4. Mead, G., H. (1934). Mind, Self and Society from the Standpoint of a Social Behaviorist, Chicago: University of Chicago Press

5. Gudykunt, W. et kim, Y. (1992). Communication With Strangers: An Approch to Interculutral Communication. New York, McGraw Hill.

6. Hofstede, G. (1991). Culture and Organisations: Software of the Mind, Londres: McGraw Hill.

7. Kaufmann, J.-C. (2004). L'invention de soi, Paris, Armand Colin.

8. Boureau, M., et Penard, T. (2016). Introduction. L'économie numérique en question. Revue d'économie industrielle, 156(4), 11-15.

9. Negroponte, N. (1997). L'homme numérique : comment le multimédia et les autoroutes de l'information vont changer votre vie. Pocket.

10. Revue Economique (2001). 52(numéro hors-série), 7-36.

11. Strucker, S and Burke, P. (2000). The Past, Present, and Future of an Identity Theory. In Social Psychology Quarterly, 63(4), 284-297.

\section{Others resources}

Stanley Millgram (1967). Expérience du phénomène "du petit monde".

The EU and the digital single market, (June 2017). European Commission. Available at: https//ec.europa.eu/commission/priorities/digital-single-market_fr.

The law for a digital republic, promulgated on October 7, 2016, France. Available at: econo-mie.gouv.fr. www.intel.com.

\footnotetext{
${ }^{1}$ Frame, A. (2008). Repenser l'interculturel en communication. Performance culturelle et construction des identités au sein d'une association européenne. Science de l'homme et Société. Université de Bourgogne.

2 KAufmann, J.-C. (2004). L'invention de soi, Paris, Armand Colin.
} 